\title{
Spatial and Temporal Principles and Methods of the Historical Urban Environment Composition Transformations
}

\author{
Margaryta Didichenko ${ }^{1,}$, , Irina Bulakh ${ }^{1}$, Olena Kozakova ${ }^{2}$ \\ ${ }^{1}$ Department of Design Architectural Environment, Kyiv National University of Construction and Architecture, Kyiv, Ukraine \\ ${ }^{2}$ Department of Information Technologies in Architecture, Kyiv National University of Construction and Architecture, Kyiv, Ukraine \\ Email address: \\ didichenko.mo@knuba.edu (M. Didichenko), irabulakh81@gmail.com (I. Bulakh), olena.kozakova.arch@gmail.com (O. Kozakova) \\ ${ }^{*}$ Corresponding author
}

To cite this article:

Margaryta Didichenko, Irina Bulakh, Olena Kozakova. Spatial and Temporal Principles and Methods of the Historical Urban Environment Composition Transformations. Urban and Regional Planning. Vol. 4, No. 4, 2019, pp. 144-151. doi: 10.11648/j.urp.20190404.13

Received: October 29, 2019; Accepted: November 23, 2019; Published: December 4, 2019

\begin{abstract}
The composition development of the historical urban environment is relevant and requires constant improvement and research conducted on the identification and analysis of internal morphological patterns basis. In order to systematize analytical knowledge and skills in determining the nature of urban changes and operation with a historical context, a system of four principles of spatial and temporal compositional transformations is proposed, describing previously revealed patterns of urban development, based on the characteristic processes of change and growth of the composition. Two methods are substantiated according to each of the principles which are designed to give a logical description of the means of embodying the systematic change of the urban planning composition, as well as to determine the immediate processes and ways of development of the composition structure. In order to remain the internal interpreting related processes logic, the article structure is formed by blocks, each defines the exact principle and justifies the two corresponded methods. Thus the principle of spatial scale is marked by a regulated controlled growth of urban planning, which is characterized by spatial scaling methods and the uniformity of structural changes. The principle of the structure balance is described by the processes of self-organized systematic stabilization of the urban composition. It corresponds to the methods of the parts comparison and system stabilization. The principle of systemic rhythmicity is determined by the internal qualitative processes of concentrating on the development of planning design and structuring of the beforehand created composite elements. It is characterized by the methods of regular alternation and the system hierarchy. The principle of compositional harmony is based on the processes of planning system external oriented adaptation and the conformity of the created composition to the principles of sustainable development. It is implemented by the methods of spatial proportionality and the evolutionary integrity of the system. For illustrates the interconnectedness of the principles, characteristic processes and patterns of spatial composition development, general compositional techniques, appropriate methods and parameters of spatial modifications of the planning structure, it is suggested to place all the data in the correlation table. This enables further methodical identifying of the inherent features and to identify the appropriate principles and methods of compositional modifications within the consideration of the new urban planning case. These research conclusions may be used in the creation of further well-founded study recommendations, which can be implemented in the renovation and revitalization of urban spatial structures projects.
\end{abstract}

Keywords: Spatial Planning, Spatial Composition, Planning Structure, Development Principles, Methods of Transformation, Harmonious Development, Urban Patterns

\section{Introduction}

The research problem of the historic cities planning structure development is not new and is becoming relevant for every successive generation of architects trying to actualize the urban environment up to the needs of today. The main questions are "what to consider as a historical environment" or "what requires preservation and how to emphasize the 
historical component" since there is no single unified solution to these problems. Each historical environment is formed by the impact of many aspects - both urban and architectural, as well as social, political and economic. That is why each city is characterized by a certain set of tools, patterns and methods that formed the basis for its formation.

The theoretical basis for determining the principles and methods of the historical development of the spatial-temporal composition of urban planning is basic research on various aspects of the formation and functioning of the historical urban environment and the ways of its reconstruction: justification of the term of the historic city [1], principles of reconstruction and interaction of the city elements [2], factors of historical cities formation [3], conceptualization of historical urban space [4], stages of urban formation on the social aspect basis [5], the principles and the development of historic urban space [6]; research of urban issues concerning processes of urban development: defining a new systematic approach to architecture [7], principles of architectural and ensemble development [8], urban planning layers and evolutionary development of planning structure [9], modeling and self-organization of urban planning systems [10], intangible impacts on city development [11], correlation the form and content of the urban environment [12], the concept of organic growth of the urban structure [13], the relationship with the typology and form of the urban environment [14], the evolutionary approach to the form and structure of the city [15, 16]; studies on the functioning and problems of composition of urban structures: definition of the city framework [17], substantiation of the method of composite analysis of the city [18], approaches to the synthesis of urban planning forms [19], compositional principles of the relation of form and space [20], questions of morphology of architectural form [21], formation and continuity in the compositional structure of historical cities [22], principles of hereditary urban development [23], aspects of aesthetics in the harmonization of urban space [24], patterns of compositional and structural development [25], aesthetic and figurative aspects of morphology of urban space [26]; philosophical and architectural searches that relate the categories of space and time in the urban planning context: the essence of urban formation [27], philosophy of the theory of space and time in the city [28], the consideration of the city as a conceptual system of networks [29], categories of time in architecture [30], the relation between time and space [31], the context of time in the social aspect of urban development [32].

Modern architectural and urban environment studies are comprehensive and affect many aspects of both the formation and certain regular changes in space and time. However, recent trends have shifted the focus to the nature and pace of urban development, and especially to the social aspects of urban habitat functioning, while assessing the compositional features of urban planning and their impact on the formation of a comfortable and aesthetically pleasing environment is practically lost. Current studies of compositional analysis are abstract and conceptual mostly. Currently, the definition and systematization of the regularity of the urban planning dynamic transformations of and their interpretation in the methods of the spatial development of the composite urban structure is a necessary step for a comprehensive analysis of the principles of modification. The logical relationship identifying between the leading characteristics of urban spatial development contributes to a more grounded approach to clarifying promising harmonious growth directions and modifications of the planning composition.

\section{The Rationale and Concept Overview}

\subsection{Study Conceptual Clarifications and Research Methods}

As far as the studies of architectural and urban composition in addition to morphology have considerable differences and are not systemized, it is suggested to propose the following conceptual apparatus. In the context of this paper, the concept of urban planning composition is regarded as space ordered system of axes and dominants, based on the key streets, squares and city centres of various purposes. At the same time, the development of space-time composition is considered as a complete architectural and planning complex and ensemble, which are gradually modified and transformed under the influence of various factors in space and time [p. 131, 33]. This just makes it possible to consider the compositional structure as a single whole, which is formed and developed according to certain patterns. The next term is the "compositional hackberry", which was defined by Mamakov as "the structural basis of the planning composition [p. 13, 18], but in this study it gains a broader significance and is regarded as a system of interconnected composite nuclei and axes that deepen the notion of characteristic construction planning and hierarchical dependence of its elements". The composite core is defined as a single planning centre or a naturally related set of contiguous dominants in an urban structure. They are characterized by a considerable size, distinctive visual or stylistic features, as well as considerable attractiveness in the organization of urban life and psychological perception. The compositional axis is regarded as the imaginary development line of the compositional structure along which infrastructural and visual connections are built [33]. In contrast to the hackberry, one may speak of the composite urban structure fabric presence which is determined by the system of supporting and minor composite elements that do not have a significant impact on the overall city development. These terms form the basis of the proposed systems study and structuring approaches to the of the patterns of the spatial development of urban planning composition.

It's agreed to explore the historical urban environment like the one which urban planning framework is formed within the previous historical stages, as well as the nature of the building, spatial connections, monuments and cultural traditions which are preserved.

The grapho-analytical study of the historical urban development of 40 major and largest cities with different initial compositional structure (eight of which are Ukrainian, sixteen European, eight Asian and eight American) are further systematized and grouped into eight methods. They are 
analyzed on the basis of the proposed method of the urban planning composition development study which is based on a comparative graphical analysis of large-scale time maps and urban plans at certain basic stages of city development. They are distinguished thanks to the analytical historical and urban planning development basis [34]. This approach makes it possible to consider the stages, characteristics and causation and the underlying patterns of spatial modifications.

To illustrate the further justification of the principles and methods of spatiotemporal modifications, it is suggested to consider two stages of the development of a particular city. These stages describe the process of implementation of a particular method, comparing the scale maps of these periods with the compositional models of the development of the composite frame drawn on them, which are idealized nuclei and axes at best. These models distinguish the compositional kernels at the consideration stage and from previous periods, as well as the stage of formation of spatial relationships by symbols ranking. Such comparative analysis allows to conduct the logical conclusions about the processes of the spatial development of the composition of the city in a certain time interval and to determine their characteristics.

\subsection{Defining and Justifying the Principles and Methods of the System of Urban Planning Composition Development in Space and Time}

Based on the theoretical studies and the experience of the spatial development of urban planning composition, it is proposed to systematize all dynamic processes of composite transformations into an interdependent system of four conceptual categories - the compositional principles, achievement of which is possible due to the use of appropriate methods. Therefore, a systematic consideration and justification of the methods of spatial-temporal transformation of the composition as a parameter of the dynamics of urban processes and levels of urban planning changes, directly relying on the definition and characteristics of pre-identified principles such as the scale of the space, structure balance, systematic rhythmicity and compositional harmony. These principles describe and systematize the identified patterns of historical urban planning development, which is based on the characteristic processes of change and growth of the urban structure morphological features, which are conceptually based and correlated with general compositional techniques. In order to save the logical interrelation of the material presented, first of all, a definition of the principle is given after which a description and justification of the methods by which it is implemented described.

\subsubsection{The Scale Space Principle}

The scale space principle is characterized by controlled quantitative growth of urban planning by dispersing the composite elements, as well as the formation of an extensive and branching planning system. Metaphorically, this principle correlates with the features of compositional scale, reflecting the comparison and interrelation of the designed form and the surrounding context. According to the proposed analogy, the growth of the planning composition is characterized by the identification and interconnection of characteristic internal relationships and divisions within a single conditionally integral initial structure. This principle is implemented on the basis of two methods - spatial scaling and uniformity of structural changes.

The spatial scaling method characterizes the ratio of newly formed environmental blocks and is determined by such means as the scalability or hypertrophy of the spatial structure. Proces of the scalability in this context is defined as the dispersed sequential centrifugal or centripetal development of composite parts based on the initial principles of structure construction. This tool is realized in the compositional Chicago suburbs historical structure development, for which the spatial expansion of the entire urban structure during the analyzed period from 1862 to 1901 is characterized (Figure 1). This process occurs on the centrifugal vectors' basis along with the directions of the basic spatial axes, formed on the initially specified scale and proportions of the composite cells. The second means of implementing the method of spatial scaling - hypertrophy — is characterized by a significant spatial exaggeration of the initial characteristics of the planning composition in one or more aspects.

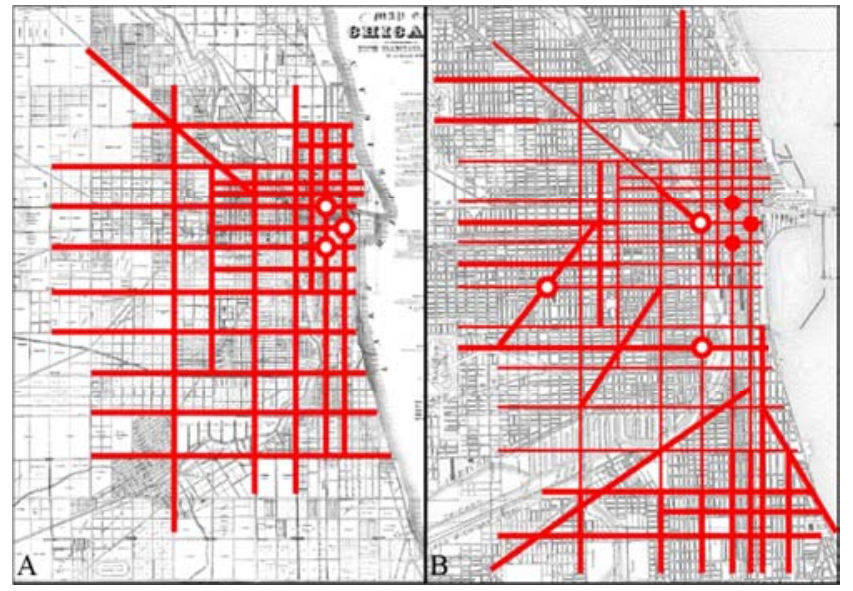

Figure 1. Schemes of the spatial scaling method application taking as the example the development of the Chicago historical center composite frame in 1862 (A) and 1901 (B). Symbols: white circle - a new dominant, red circle existing dominant; bold red line - the new axis, thin red line - existing axis.

The method of uniformity of structural changes describes compositional development in the vector of spatial transformations aspect. It is defined by the typology of dispersion processes of composite elements, and its implementation is based on such tools as regularity and asymmetry. The first means - regular changes - is characterized by processes of uniform distribution of the parts of elements and blocks of the spatial structure. This tool is illustrated by the compositional changes of the historic layout of the city of Vienna in the period from 1872 to 2016 (Figure 2 ). This stage of the city centre development is inherent with spreading of branches of the existing structure in accordance with the pre-formed distribution of space elements within the limits determined by the initial directions of formation of the city composition. In contrast, asymmetric changes are 
determined by the unidirectional vector of compositional development and spatial modifications.

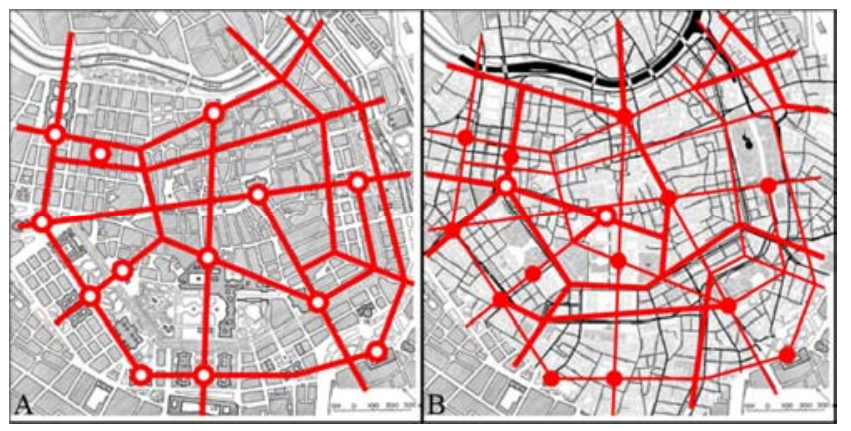

Figure 2. Application of the uniformity of structural changes method schemes based on the example of the composite frame of the historical center of Vienna development in 1872 (A) and 2016 (B). Symbols: white circle - a new dominant, red circle - existing dominant; bold red line - the new axis, thin red line - existing axis.

\subsubsection{The Principle of the Structure Balance}

The principle of the structure balance is described by the process of stabilization of the urban planning system composition due to internal processes of self-organization and compaction of the layout. On the metaphorical level, this process can be compared with the basic principles of composition tools -- contrast and nuance, which determine the difference or similarity of various properties of elements within a single composition. This analogy is conditioned by the nature of building relationships of diverse planning elements within the framework of shaping processes in order to preserve a coherent urban structure. The methods of parts comparison and system stabilization are in line with this principle.

The method of parts comparison describes the characteristics of the ratio of newly formed and structure-forming compositional elements. It is based on the contrast or the nuance dependencies. The first means - the contrast - is characterised by the contrasting of the composite core to the whole structure with one of the spatial parameters. The historical range of the compositional structure of the Moscow city the period from 1893 to 1966 could be taken as an example (Figure 3). They originally formed compact radial-annular structure dynamically expanded along the established axes following a radial character. Comparing the area of the original model and the newly formed, one may note a significant contrast of changes in the spatial characteristics of the composite frame in this period. The nuanced dependencies within the comparing method are characterized by the system spreading according to the proportional sub-centres and axes development.

The second method - system stabilization — that is consistent with the principle of balance is the stabilization of a system that describes the equilibrium of spatial articulations based the interaction of various system elements and is determined by the subordination, comparison, dependencies and connectivity of the elements. The subordination is characterized by a clear hierarchical dependence of elements of the composite frame and ground, such as, for example, the historical suburb of Berlin, which was significantly destroyed by hostilities and subsequently restored within the originally laid-out composite axes and centres, but in updated inner space figure (Figure 4). In this case, modification of minor and supporting compositional elements can be considered as a process subordinate to the basic spatial structure. The second means of the system stabilization method implementing is comparison. It is determined by the independent processes of development of several composite cores or composite cells that do not have a direct connection. The dependency of the components of the composite frame is characterized by their systemic connectivity, that is, the development of one of the parts leads to a change of each component in the overall structure. Connectivity is characterized by independent processes of modifying structurally related compositional elements, without significantly affecting each other or the overall structure as a whole.

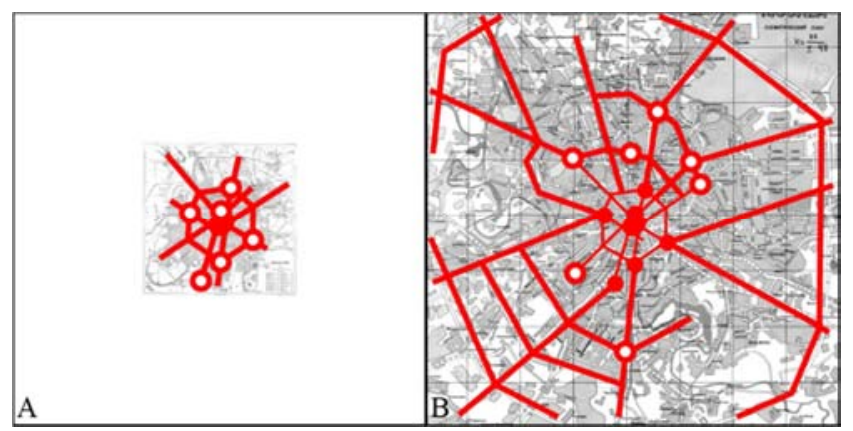

Figure 3. Application schemes of the parts comparison method taking as the example the development of the composite frame of the historical center of Moscow city in 1893 (A) and 1966 (B). Symbols: white circle - a new dominant, red circle - existing dominant; bold red line - the new axis, thin line - existing axis.

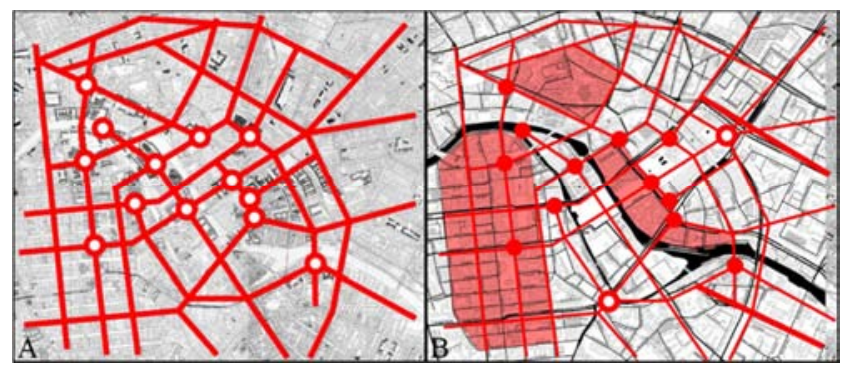

Figure 4. Application schemes of the stabilization method taking as the example the compositional frame of the historical center of Berlin city in 1920 (A) and 2016 (B). Symbols: white circle - a new dominant, red circle - existing dominant; bold red line - the new axis, thin red line - existing axis.

\subsubsection{The Systemic Rhythm Principle}

The systemic rhythm principle is determined by the internal qualitative processes of concentrating on the development of the planning and structuring of pre-formed composite tools. The defined principle is based on such a compositional tool as rhythm-metric ratios, that describe the nature of regularities in the alternation of homogeneous elements and the space between them. Taking it as an analogy, the principle is characterized by the subordination of processes of internal systematization of structural elements to certain interdependent patterns within the development of a coherent 
initial character of planning. The principle of systemic rhythmicity is characterized by methods of regular alternation and the hierarchy of the system.

The first method - regular alternation - describes the type of repetition of composite elements and, accordingly, has a rhythmic or syncopal character. The rhythmic tool is a dynamic development of the structure on the basis of regular repetitions of characteristics or structural elements. The development of the historic centre of Paris between 1800 and 1870, which includes the so-called Ottoman Reorganization could be taken as an example (Figure 5). During this period, the cross-axis connected to the star centres were laid on the basis of the use of interconnected rhythms of space. Syncopation means of development of the compositional structure are characterized by the processes of point intra-compositional changes subordinated to the general compositional system.

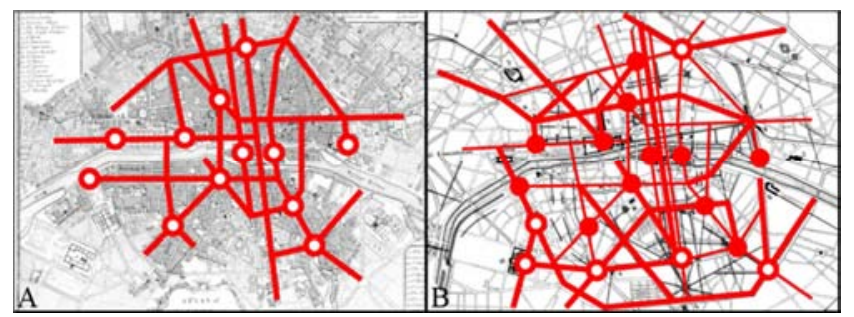

Figure 5. Application schemes of the systematic rhythm method taking as the example the development of the historical center of Paris composite frame in 1800 (A) and 1870 (B). Symbols: white circle - a new dominant, red circle existing dominant; bold red line - the new axis, thin red line - existing axis.

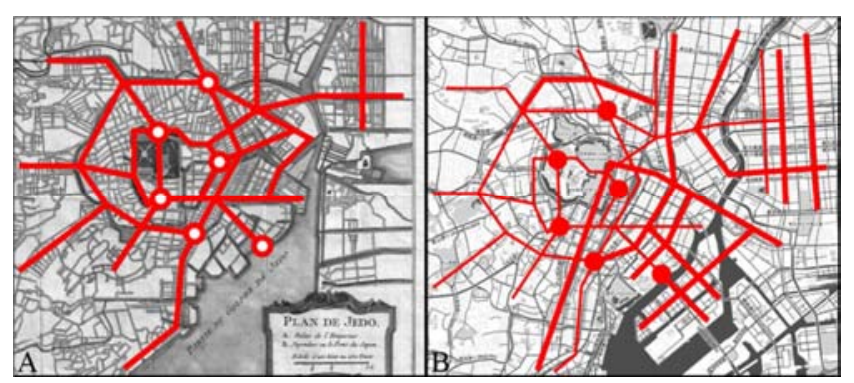

Figure 6. Application schemes of the hierarchy system method taking as the example the historical compositional frame city center of Tokyo development in 1752 (A) and 2016 (B). Symbols: white circle - a new dominant, red circleexisting dominant; bold red line - the new axis, thin red line - existing axis.

The second method of the systemic rhythm principle is the system hierarchy. It is justified by the natural dependencies between structural parts and is implemented by subordination or equivalence. The subordination is characterized by the development of newly formed elements in a rigid system of subordination and the ranking of the compositional weight of structural parts. In this coherence, the development of the historical Tokyo city centre from 1752 until nowadays could be researched. Based on cultural traditions, The development of the historical area composition happened to take into account the hierarchical subordination of all elements to the main nucleus - the castle of Edo, which is up to nowadays one of the prominent spatial elements (Figure 6). The balance, as a means of embodying the hierarchy system method, is achieved by regular equivalents to the existing elements of changes in the compositional frame.

\subsubsection{The Principle of Compositional Harmony}

The principle of compositional harmony is based on the processes of adapting the planning system to external elements and structures, as well as the conformity of the formed composition to the principles of sustainable development. Metaphorically, this principle relies on the primary tool of achieving compositional harmony proportionality. It describes the nonlinear relations of elements within a coherent system. The overall system balance and harmonious sustainable development are ensured. Based on the adaptation of the elements of the urban layout composition, the uniform patterns of growth of the parts and the whole achieve the overall balance based on two corresponded methods -- of the spatial proportionality or of the evolutionary integrity of the system method.

The method of spatial proportionality is determined by the type and alignment parameters of the composite parts of the structure and the external elements on the basis of modular or irrational regularities. The modular relationships of the elements of the structure and the surroundings determine the rational process of their interaction and the regulated process of growth of the holistic system, such as the historic centre of New York in the time period of 1916 till 2016. Its composition is planned to be concentrated within the original cell module (Figure 7). Scaling of space occurs through compaction and adaptation of the structure of existing spaces and relationships to the new socio-economic challenges of the city. The use of irrational regularities within the embodiment of the method of spatial proportionality over a similar principle is imposed on the spatial composition of the urban structure.

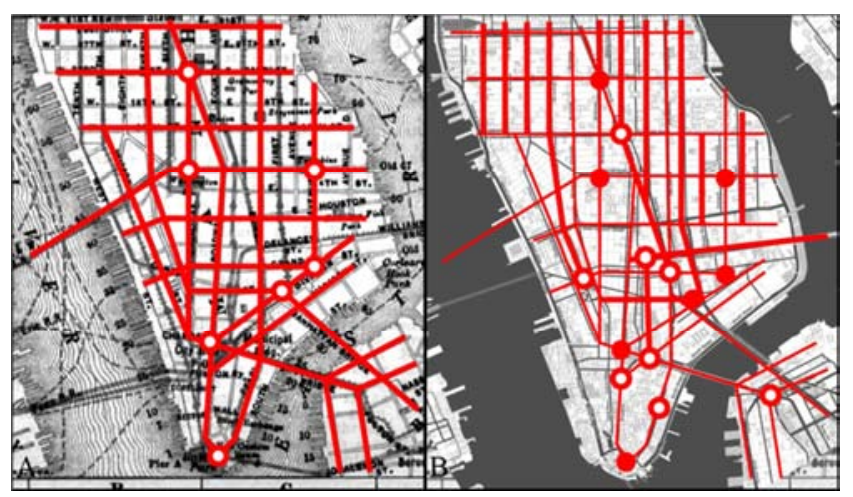

Figure 7. Application schemes of the compositional harmony principles taking as the example the historical compositional city center frame of New-York city in 1916 (A) and 2016 (B). Symbols: white circle - a new dominant, red circle - existing dominant; bold red line - the new axis, thin red line - existing axis.

The method of evolutionary integrity of the system is characterized by the determination of the internal balance of the dynamic structure based on the straightness or discrete feature spatial development of the urban composition. The straightness of structural alteration processes is conditioned by the consistent step-by-step development of the composite frame, based on internally defined regularities. For example, 
the historical development of the centre of London from 1750 till now is clearly characterized by the processes of continuous alteration of the internal structure with the change of conceptual patterns of spatial relations, but relying on certain composite nuclei (Figure 8). In summary, spatial changes replace each other, forming an integral dynamic space-time composition. The discrete spatial urban planning development is justified by the transformation of the internal structure by discontinuous or jumping vectors, based on changes in the direction or nature of dynamic transformations. In addition, the development can be attributed to complete cycles of spatial modifications with further conservation of certain compositional structure elements. Thus, the urban structure becomes permanent partly developed.

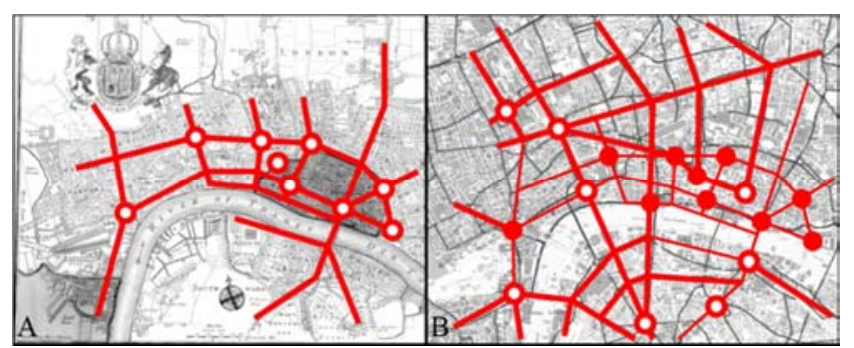

Figure 8. Application schemes of the evolutionary integrity method taking as the example the historical compositional frame city center of London in 1750 (A) and 2013 (B). Symbols: white circle - a new dominant, red circle - existing dominant; bold red line - the new axis, thin red line - existing axis.

\section{Results and Discussion}

The revealed and thoroughly described the four principles and corresponding to the eight methods of spatial-temporal transformation of the historical urban environment composition, may serve as the result of the study presented in the article. All of them depicts the patterns of the spatial development of urban morphological structures. The justification of the four principles (space scale, structure balance, systemic rhythm and compositional harmony) gives ideas of the basic processes that characterize the development of the compositional structure (controlled growth, systemic self-organization, internal structural concentration, as well as the externally oriented adaptation) and defines the processes of space-time compositional modifications (branching, stabilization, structuring, adaptation). An important perspective is to find out the consistency of the proposed system principles with gross compositional tools (scale, ratio, rhythm and proportion) that provides a logical interconnection of proposed and fundamental concepts. Each principle is accompanied by the two appropriate methods that characterize the processes of an embodiment of systemic changes in the urban planning composition. The scalability principle corresponds to the methods of spatial scaling and uniformity of structural changes; the principle of the structural balance is realized on the basis of methods of parts comparison and stabilization of the system; the principle of systemic rhythm is described by the methods of regular alternation and hierarchy of the system; the principle of compositional harmony is embodied by the methods of spatial proportionality and the evolutionary integrity of the system. These methods are justified on the basis of determining the nature of the spatial changes in the ratios of elements (dispersion, interdependence, repeatability or concordance) and articulations (uniformity, equilibrium, regularity, balance) of the compositional system. Each method is aligned with the mediums of the embodiment of spatial compositional change, describing in various ways approaches to their realization: scale or hypertrophy; regular or asymmetric changes; contrast or nuance; subordination, matching, dependency or connectedness; rhythm or syncope; subordination or equivalence; modularity or irrationality; continuity or discretion.

It is proposed to place this discovered system in Table 1 that clearly illustrates the linear correspondence and interrelation of processes, principles, methods, means of their implementation and the nature of systemic changes. Table 1 visualization might be used for further analyzing the new cases. What is more, it makes it possible to quickly identify the nature of the development of a particular historic city and the corresponding processes of spatial modification.

Table 1. The interrelation of the spatial-temporal transformations of the historical urban environment composition.

\begin{tabular}{llll}
\hline $\begin{array}{l}\text { The development principle of } \\
\text { space-temporal composition }\end{array}$ & $\begin{array}{l}\text { The process that characterizes the } \\
\text { compositional structure development }\end{array}$ & $\begin{array}{l}\text { The nature of the compositional } \\
\text { Common composition tools } \\
\text { change process }\end{array}$ \\
\hline $\mathbf{1}$ & $\mathbf{2}$ & $\mathbf{3}$ & $\mathbf{4}$ \\
\hline The space scale & Controlled growth & Scale & Branching \\
Structure balance & Systematic self-organization & Ratio & Stabilization \\
Systemic rhythm & Internal structural concentration & Proportion & Adaptation \\
Compositional harmony & Externally oriented adaptation & & \\
\hline
\end{tabular}

Table 1. Continued.

\begin{tabular}{|c|c|c|c|}
\hline $\begin{array}{l}\text { The development principle of } \\
\text { space-temporal composition }\end{array}$ & $\begin{array}{l}\text { The method of space- temporal } \\
\text { composition transformations }\end{array}$ & $\begin{array}{l}\text { The sort of the composition } \\
\text { system changes }\end{array}$ & $\begin{array}{l}\text { A means of embodying spatial } \\
\text { compositional change }\end{array}$ \\
\hline 5 & 6 & 7 & 8 \\
\hline \multirow{2}{*}{ The space scale } & Space scaling & Dispersal of parts & $\begin{array}{l}\text { Scalability } \\
\text { Hypertrophy }\end{array}$ \\
\hline & The uniformity of changes & Uniformity of parts & $\begin{array}{l}\text { Regular changes } \\
\text { Asymmetry }\end{array}$ \\
\hline
\end{tabular}




\begin{tabular}{|c|c|c|c|}
\hline $\begin{array}{l}\text { The development principle of } \\
\text { space-temporal composition }\end{array}$ & $\begin{array}{l}\text { The method of space- temporal } \\
\text { composition transformations }\end{array}$ & $\begin{array}{l}\text { The sort of the composition } \\
\text { system changes }\end{array}$ & $\begin{array}{l}\text { A means of embodying spatial } \\
\text { compositional change }\end{array}$ \\
\hline 5 & 6 & 7 & 8 \\
\hline \multirow{5}{*}{ Structure balance } & Parts comparison & Interdependence of elements & $\begin{array}{l}\text { Contrast } \\
\text { Nuance }\end{array}$ \\
\hline & \multirow{4}{*}{ System stabilization } & \multirow{4}{*}{ Equilibrium of parts } & Subordination \\
\hline & & & Comparison \\
\hline & & & Dependence \\
\hline & & & Connection \\
\hline \multirow{3}{*}{ Systemic rhythm } & Regular alternation & Repeatability of elements & $\begin{array}{l}\text { Rhythm } \\
\text { Syncopation }\end{array}$ \\
\hline & \multirow{2}{*}{ System hierarchy } & \multirow{2}{*}{ Regularity of parts } & Subordination \\
\hline & & & Equivalence \\
\hline \multirow{2}{*}{ Compositional harmony } & Spatial proportionality & Coordination of elements & $\begin{array}{l}\text { Modularity } \\
\text { Irrationality }\end{array}$ \\
\hline & Evolutionary integrity & Balance of parts & $\begin{array}{l}\text { Straightness } \\
\text { Discretion }\end{array}$ \\
\hline
\end{tabular}

\section{Conclusions}

The argumentation of these four principles and the corresponding methods of spatial-temporal urban planning composition development gives the basis for further analytical approach to research and description of the processes of dynamics of urban changes of historical environment of any kind. The proposed interconnected system is an important aspect in the development of further research recommendations, systematization, search of predicted and regular ways of development of the urban framework composition, as well as in determining the character of the development of territories of urban structures renovation and revitalization projects.

\section{References}

[1] K. Kushnaryova "To the definition of the essence of the concept of the historical city" Architectural Review KNUCA, 2018, Issue 16, pp. 88-97.

[2] V. A. Lavrov (1977). The development of the planning structure of historically developed cities. Moscow: Stroyizdat. $196 \mathrm{p}$.

[3] V. L. Glazychev (2008). Urban Studies. Moscow: Ed. Europe. $220 \mathrm{p}$.

[4] A. R. Cuthbert (2006). The form of cities. Wiley-Blackwell. $328 \mathrm{p}$.

[5] P. J. Larkham and M. P. Conzen (2014). Shapers of urban form: explorations in morphological agency. Routledge. $360 \mathrm{p}$.

[6] M. Davies (2003). Design in the Historic Environment. The Building Conservation Directory. Available: https://www.buildingconservation.com/articles/design/design. htm.

[7] I. A. Dobritsyna (2004). From postmodernism to non-linear architecture: architecture in the context of modern philosophy and science. Moscow: Progress-Tradition. 416 p.

[8] I. V. Korotun (2006) Principles of architectural and planning organization of ensemble building. Kyiv: KNUCA. 20 p.

[9] V. O. Timokhin (2008). The architecture of all development. 7 books on urban theory. Kyiv: KNUCA. 629 p.

[10] A. Hoblyk "Newtonian analog method in modeling the effects of urban planning self-organization" Space \& form: scientific journal, 2015, Issue 24/2, pp. 67-76.

[11] M. M. Gabrel, M. M. Kosmiy "Intangible factors and qualitative characteristics in the formation of spatial structures of the city. Historical Context" Architectural Review KNUCA, 2018, Issue 17-18, pp. 300-319.

[12] B. Hillier "What are cities for? And how does this relate to their spatial form?" UCL: The Journal of Space Syntax, Issue 6/2, 2016, pp. 199-212.

[13] A. E. J. Morris (1994) History of Urban Form. Longman Scientific \& Technical. 456 p.

[14] M. Berghauser-Pont and P. Haupt (2010). Spacematrix. Space, Density and Urban Form. NAi Publishers. 280 p.

[15] K. Kropf "Aspects of urban form" Urban Morphology, 2009, Issue 13, pp. 105-120. Aviable: http://www.urbanform.org/online_public/2009_2.shtml.

[16] K. Kropf (2017) The handbook of urban morphology. Wiley. 248 p.

[17] A. E. Gutnov (1985). The world of architecture: the language of architecture. Moscow: Young Guard. 351 p.

[18] N. V. Mamakov (1990) City: the experience of compositional analysis. Publishing house of Kazan University. 189 p.

[19] A. G. Rappaport (2002) To the understanding of the architectural form. Moscow: NIITAG RAASN. $140 \mathrm{p}$.

[20] F. Chin (2005) Architecture: form, space, composition. Moscow: AST: Astrel. 399 p.

[21] N. Kozodaeva "Morphology of the architectural form" Cultural studies analytics, 2010, Issue 2 (17). - Aviable: http://analiculturolog.ru/архив-журнала/2010-year/выпуск-217-2010.

[22] Y. I. Yegorov "Contemporary Problems of Formation of the Spatial Composition of the Historic Cities of Ukraine" Contemporary Problems of Architecture and Urban Planning, 2013, Kyiv: KNUCA, Issue 33, pp. 235-242. 
[23] T. Y. Kutuzova (2016) Patterns of compositional development of regular historical plans in Ukrainian cities. Kyiv: KNUCA. 21 p.

[24] G. I. Bolotov "The role of the aesthetic alternative in the process of urban space management and its harmonization" Modern problems of architecture and urban planning, 2019, Kyiv: KNUCA, Issue 53, pp. 100-109.

[25] S. Kostof (1991) The City Shaped: Urban Patterns and Meanings Through History. Thames \& Hudson. 352 p.

[26] E. H. Gombrich (1999) The uses of Images. London: Phaidon Press Limited. 304 p.

[27] G. I. Revzin (2002) Essays on the philosophy of architectural form. Moscow: OGI. $144 \mathrm{p}$.

[28] L. A. Radionova, N. V. Snitsar "Space and time in architecture in a historical and philosophical context" Communal services of cities, 2007, Kyiv, Issue 79, pp. 423-427.

[29] E. G. Trubina (2011) City in theory: experiments on the comprehension of space. Moscow: New Literary Review. 520 p.

[30] H. A. Ohrim "The Interpretation of the Category of Time in Architecture"Architectural Review KNUCA, 2018, Issue 11, pp. 206-212.

[31] J. Till "Architecture in Space, Time" Architecture and Anthropology, 1996, Issue 3, pp. 12-16.

[32] T. Hinse (2014) The Morphology of the Times: European Cities and their Historical Growth. DOM Publishers. 304 p.

[33] M. O. Didichenko "Definition and rating of the morphology landmarks of the urban planning system" Urban planning and territorial planning, 2018, Issue 68, pp. 130-139. Aviable: http://nbuv.gov.ua/UJRN/MTP_2018_68_19.
[34] M. O. Didichenko "The research method for studying the development of the composition of urban planning in the space and time" Urban planning and territorial planning, 2017, Issue 65, pp. 158-165. Aviable: http://nbuv.gov.ua/UJRN/MTP_2017_65_23.

[35] I.V. Bulakh "Artistic and Aesthetic Formation and Evolution of Architectural and Urban Planning" Space. Science and Innovation, 2019, Issue 5 (5), pp. 57-66. DOI: 10.15407/scine15.05.057.

[36] G. Kovalska, I. Merylova, I. Bulakh "Urban improvement of comprehensive schools and out of school educational establishments in Ukraine" International Journal of Innovative Technology and Exploring Engineering (IJTEE), 2019, Vol. 8, Issue 12, pp. 1765-1770. DOI: 10.35940/ijitee.L3229.1081219. Aviable: https://www.ijitee.org/wp-content/uploads/papers/v8i12/L322 91081219.pdf.

[37] I. Bulakh, L. Kozakova, M. Didichenko "The innovative trends in architecture and urban planning of health care institutions" International Journal of Innovative Technology and Exploring Engineering (IJITEE), 2019, Vol. 9, Issue 1, pp. 317-323. DOI: 10.35940/ijitee.A4111.119119. Aviable: https://www.ijitee.org/wp-content/uploads/papers/v9i1/A4111 119119.pdf.

[38] I. V. Bulakh "Common Features of Architectural Design of the Medical Purpose" Building. Science \& Technique, 2019, Issue 18 (4), pp. 311-318. 10.21122/2227-1031-2019-18-4-311-318 Aviable: https://sat.bntu.by/jour/article/view/1990. 